\title{
Did you hear "7 Rings" or "My Favorite Things"? Ariana Grande's Spin on a Classic Rodgers and Hammerstein Song Could Have Lasting Impact on an Iconic Brand and the Bottom Line
}

\author{
Melissa Wald \\ Middle Tennessee State University \\ This paper was presented at the 2019 International Summit of the \\ Music \& Entertainment Industry Educators Association
}

March 21-23, 2019

https://doi.org/10.25101/19.19

\section{Abstract}

Fifty-four years after the release of The Sound of Music, Rodgers and Hammerstein have a number one hit. Using the melody of the classic song "My Favorite Things" and what is being termed a "reinterpretation" of the lyrics, Ariana Grande has created a new work which describes her favorite things resulting from a trip to Tiffany's. The materialism portrayed is completely opposite to the original lyrics, which spoke of sweet, simple things that money cannot buy.

This paper explores several of the issues that a musical work of this type might generate. The most obvious one is the copyright ownership and the participation of the original writers. In addition, this paper investigates the impact of the release on the wholesome brand of The Sound of Music. Clearly there is a financial benefit of owning a copyright with this level of success. But what will be the social impact? Is the immediate success of "7 Rings" indicative of the culture of this generation? This paper provides an overview of the comments in response to the release as well as explores the decision-making process by the rights-holders and the balance between the benefit of introducing The Sound of Music to a new generation of fans and the risk of altering the brand.

Keywords: 7 Rings, Concord Music, Music Publishing, Copyright, Ariana Grande, My Favorite Things, Rodgers and Hammerstein

\section{Introduction}

On January 18, 2019 Ariana Grande released what would be the second single from her album Thank U, Next entitled, "7 Rings". This release came immediately following a seven-week run at No.1 for the title track. "7 Rings" debuted at No.1 on the Billboard Hot 100 Chart and would surpass the previous single by one week with a reign of eight weeks in the No. 1 spot. While this level of success is not surprising for an artist of this stature, what is unusual about this release is the content of the song itself. As soon as Grande begins singing, it is clear that this new song incorporates the distinctive melody of the fifty-four year old iconic song, "My Favorite Things" from The Sound of Music. This was immediately intriguing to this life-long Sound of Music fan and what follows is a description of steps taken to inquire about the process, the permissions granted, and the opinions of the rights-holders as to the risk of blending such a wholesome, iconic song with a pop artist's "re-interpretation" of the lyrics.

\section{Sample?}

"The pop song charts are alive with The Sound of Music" (Hershberg 2019). Indeed they were, as was the internet. "7 Rings" had been on the charts for a little over a week and there were already many articles referencing Grande's new single and "My Favorite Things". However, all of the articles located described Grande's use as a sample. Clearly it was not a case of sampling, but an original work with different lyrics. Knowing that an artist at this level would not take a chance on a use of this type without permission, I attempted to locate someone who might be able to shed light on what had occurred. As someone who operates in the music publishing space, finding information on older songs is usually quite simple. I decided to locate the owners of "My Favorite Things" and send a short message requesting 
information that could be shared with students. To be honest, I did not expect a return email any time soon, if at all.

\section{Rodgers \& Hammerstein}

Before noon the next day, I received a call from Dana Saltzman Siegel, Vice President of Marketing and Business Development for Rodgers \& Hammerstein. Obviously, my email had been quickly routed from Concord Music to the Rodgers \& Hammerstein ( $\& H)$ corporate offices. Being a bit surprised by the call and admittedly unprepared for the conversation, she graciously began by providing some details as to how this use transpired and her role in the process. At that point she allowed me to ask questions and was very forthright in answering while maintaining some confidentiality as to percentage splits, etc. In Ms. Siegel's words, "the management team for Ms. Grande was very respectful of the song and the resulting shares of the new copyright reflect this understanding." (The publisher share of $90 \%$ would ultimately be released in a Billboard.com article on March 19, 2019) (Cirisano 2019).

Ms. Siegel also shared some of the questions and concerns on which her team had deliberated during the short decision-making process. She said, "When considering this type of use, they must not only consider the value of the copyright but also the brand of The Sound of Music, both the movie and the theatrical production. What impact could this have on the brand?" She also expressed concern as to whether or not people watching The Sound of Music would hear the new lyrics in their heads rather than the original. After some discussion, the R\&H team felt this was not likely.

One fact that played a role in their decision was that Grande has a theatre background. She began her career in 2008 (at the age of fifteen) in the Broadway musical 13. Given this information, it was felt she would have some credibility in the Broadway community. In closing, Ms. Siegel stated that she was " $100 \%$ on board" with the decision and hoped it would help expand the brand of Rodgers \& Hammerstein and The Sound of Music, reaching a new generation of fans.

\section{Eight New Co-Writers and Copyright Infringement}

While the copyright for "My Favorite Things" by Richard Rodgers and Oscar Hammerstein II remains unchanged, these two men have been included as co-writers on the new work, "7 Rings". In the weeks that followed the release, there were many articles describing some artist's concerns that Ms. Grande had "borrowed" something from their work. Soulja Boy, 2 Chainz, and Princess Nokia have all been vocal about several elements in the B-section of "7 Rings", claiming Grande borrowed either a phrase or "beats" with the most obvious being, "I want it, I got it" (Jenkins 2019).
Without getting too involved in the legalities of pop stars borrowing things from each other, the thought of two deceased songwriters being wrapped up in a court case for infringement is of course impossible but somewhat interesting to think about. How would that work? Rodgers and Hammerstein could of course not be held liable for any infringement for they were not present during the creation of this new work, but with their publishing company owning $90 \%$ of "7 Rings", the company would no doubt be financially impacted by any infringement cases. And we cannot forget about the potential impact on the brand.

\section{The Sound of Music Brand}

In referring to the brand of the Sound of Music, the only true way to measure it is to look at some of the facts:

- The Broadway production premiered in 1959 and ran successfully for three years with 1,443 performances.

- In 1960 the production won five Tony Awards and a Grammy Award for Best Musical Show Album (Salzburg 2019).

- The movie has raked in $\$ 158$ million in worldwide box-office sales since its release in 1965 . When that total is adjusted to reflect current ticket prices, the film's overall gross is the equivalent of nearly $\$ 1.2$ billion today. This puts it in third place on the list of the highest-grossing movies ever, just behind Star Wars (Huddleston 2015).

- The NBC Production of "The Sound of Music Live!" in December of 2013 marked the first live television production of a musical in over fifty years. Starring Carrie Underwood as Maria, it was seen by over 44 million people.

It comes as no surprise that this production and enormously popular movie represent an iconic brand. Notice the choice of Carrie Underwood for Maria in the live television production. While Ms. Underwood's live performances have become more edgy in recent days, at that time she presented a very wholesome image. One watch of the video for "7 Rings" tells the viewer that Ms. Grande's "reinterpretation" of the lyrics is certainly not wholesome.

In his Forbes magazine article, Marc Hershberg says, "Grande had transformed the meaning of the innocent tune. Instead of being a sweet song about the simple things in life, the popular singer had turned it into an ode to materialism. She replaced an appreciation of "raindrops on roses and whiskers on kittens" with demands for "breakfast at Tiffany's and bottles of bubbles." The contrast between the sweetness and simplicity of the original and the consumerism of her version to me is a comment on the world today" (Hershberg 2019). 
Jenny Singer writes on The Schmooze, "7 Rings is so viciously materialist it reads in places like a parody of consumption. Is there any chance this number, which after all plays on a classic tune about finding joy in small moments and simple objects, is a clever commentary on gratuitous capitalist culture?" (Singer 2019).

When asked about the final decision to allow this use, Ted Chapin, who oversees the R\&H catalog of songs said, "We are always open to the notion of modern artists having a new look at Rodgers and Hammerstein and their work. While this song is certainly far from The Sound of Music, it shows just how strong and resilient the songs written by Richard Rodgers and Oscar Hammerstein II are." He continued, "we do not want to be fuddy-duddies, or even be considered fuddy-duddies. I've always felt, keep your ear to what's going on outside these four walls" (Hershberg 2019). Interestingly, Ms. Grande's release comes at the same time Mr. Chapin announced a new campaign entitled, $R \& H$ Goes Pop! This is a video series that "aims to preserve the legacy of Rodgers \& Hammerstein by inspiring artists to interpret their classics in a contemporary light" (Leight 2019).

Considering the power of the original work and the fan base, the risk taken and the percentage of copyright secured in the new work, it seems Mr. Chapin's decision has paid off with a song in this catalog topping the pop charts for the first time in history.

\section{Is There Precedence for This Type of Use?}

The incorporation of "My Favorite Things" into a pop song is certainly not a new practice in the music business. Many artists have either sampled or incorporated sections of previous works from both the theatre and previous popular hits. A related example involving an R\&H song would be Gwen Stefani's use of "Lonely Goatherd" as part of her single "Wind It Up" released in December of 2006. The horns of the original song are heard over the new tune's hip-hop beat (Hernandez 2006). The song begins with lyrics from the original and then quickly changes to the new lyrical content. Stefani shares writing credit with Rodgers and Hammerstein as well as producer Pharrell Williams. For this track, Rodgers \& Hammerstein received a 50\% share of the new work. Could the discrepancy between this deal and Grande's reflect the greater negotiating power of Concord Music? Or could it simply be that "My Favorite Things" is the more iconic and therefore valuable track? (Sisario 2019).

Ms. Stefani had previously released a song entitled "Rich Girl" which incorporates a portion of the lyrics from the Fiddler on the Roof song "If I Were A Rich Man", written by Jerry Bock and Sheldon Harnick. While this song is owned by Rodgers \& Hammerstein as music publishers, the reason this example is a bit different is that the two songwriters were alive and therefore given the opportunity to approve of the use. A common provision in songwriter contracts with music publishers is the right of approval for any changes in English lyrics. Therefore, approval must be sought from both the music publisher and the songwriter(s) (Brabec and Brabec 2018, 48). Sheldon Harnick was eighty years old at the time he gave permission and was pleased with the song's popularity, especially with his grandchildren. He was quoted as saying, "I guess you could now say grandpa's hip" (CK 2005).

\section{Would Rodgers and Hammerstein Have Approved?}

In 2009 the families of Rodgers and Hammerstein sold the business for a reported $\$ 225$ million to the Imagem $\mathrm{Mu}-$ sic Group. In 2017 Imagem was acquired by Concord Bicycle Music, which is now known as Concord Music. The previously mentioned Ted Chapin has been the executive in charge of the management of the $\mathrm{R} \& \mathrm{H}$ copyrights since 1981 (Purdum 2018, 318). In an interview with the New York Times in March of 2019, Mr. Chapin refers to Mary Rodgers, Richard Rodgers's composer daughter who died in 2014, stating that she "would have thought this is pretty kick-ass" (Sisario 2019). He goes further to share a previous commercial deal in which Richard Rodgers, who died in 1979, approved a Clairol ad that changed a famous lyric from South Pacific: "I'm gonna wash that gray right outta my hair." Chapin said of this approval, "The fact that Rodgers had agreed to that in his lifetime gave all of us a little license to feel that we should keep an open mind on these kinds of things" (Sisario 2019).

\section{Rodgers and Hammerstein as Songwriters and Music Publishers}

A quick perusal of the song listings of Richard Rodgers and Oscar Hammerstein II is a walk through decades of hit songs, some written by both of them together, and some written by either Rodgers or Hammerstein and another co-writer. However, when these two gentlemen did collaborate, there are no additional co-writers listed. According to the book Something Wonderful: Rodgers and Hammerstein's Broadway Revolution by Todd S. Purdum, "both could be chary with collaborators, stingy with credit, and notoriously tight with a buck" (Purdum 2018, 9). Many collaborators were either not credited, or were relegated to "arranger" when they truly had contributed to the compositions and in many cases were the sole composers.

One such example was that of Joshua Logan, who was a co-writer with Rodgers and Hammerstein on the script for South Pacific. Mr. Logan had understood that his name as director (on the poster) was to have appeared in the same size type as Rodgers and Hammerstein as authors. After a meeting with Hammerstein and his attorney, his name was 
reduced to $60 \%$ of that size and his co-author credit would appear the same way. They also informed Mr. Logan that he would not share in the copyright or author's royalties on the play, but only would retain his director's royalties for the run of the original company. Hammerstein was quoted as saying, "Rodgers and Hammerstein cannot and will not share a copyright. It's part of their financial structure. Including you would weaken our position" (Purdum 2018, 162).

This legal stance would continue through many of the collaborations to come. Trude Rittman, a German-born classically trained composer and arranger began working with $\mathrm{R} \& \mathrm{H}$ during the production of Oklahoma! Ms. Rittman would often devise dance music, scenic underscoring, and unforgettable choral and vocal arrangements for Richard Rodgers, while not receiving writer credit, but listed as "arranger". Rittman is responsible for the ballet music related to the dance scene in The King and I. The great bulk of the music in the fifteen-minute ballet was hers alone, but the name on the published score is Richard Rodgers (Purdum $2018,194)$ It was Rittman who created the clever choral arrangement, "Do-Mi-Mi / Mi-So-So / Re-Fa-Fa / La-Ti-Ti," that mimicked the sound of Swiss bell ringers, that would "lodge happily and permanently in the heads of listeners the world over" (Purdum 2018, 276).

Based on this information and the direct quote from Oscar Hammerstein regarding the sharing of a copyright, it seems relatively easy to make the assumption that Rodgers and Hammerstein would not have allowed the addition of eight songwriters, and a complete change of subject matter, for what could arguably be deemed one of their greatest compositions.

\section{In Closing}

Did Mr. Chapin and the team at Concord Music and Rodgers \& Hammerstein succeed? Did "7 Rings" introduce The Sound of Music to a new generation of fans? To answer this question, we can turn to facts and data collected during the first few weeks after the release.

- 85 Million streams in the first week of release

- People who no longer buy music, bought this track with close to 100,000 downloads

- Pop radio programmers were favorable, considering two previous Grande singles were still in the Top Ten rotation. "7 Rings" reached more than 27 million listeners on the airwaves the week of release (Leight 2019)

Of course all this information only proves that "7 Rings" is a hit song for Ariana Grande. But remembering that the R\&H team wanted to introduce The Sound of Music to a new generation, one must look at the underlying work, "My Favorite Things". Choosing the most popular recording of this song, recorded by Julie Andrews as part of the soundtrack for the movie, a look at the streaming data shows a very distinctive trend. According to BuzzAngle Music, this track receives a small bump in streaming activity each year during the Christmas season, as The Sound of Music movie is often shown on network television during the holiday month. But what happened the week of the "7 Rings" release is remarkable.

Figure 1 depicts the streaming data for "7 Rings" and Figure 2 depicts "My Favorite Things".

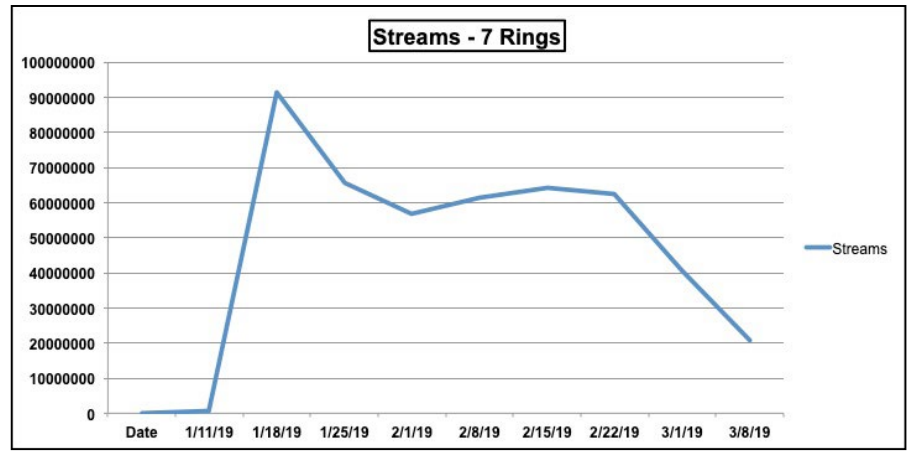

Figure 1: Streams of "7 Rings" (source: BuzzAngle Music 2019).

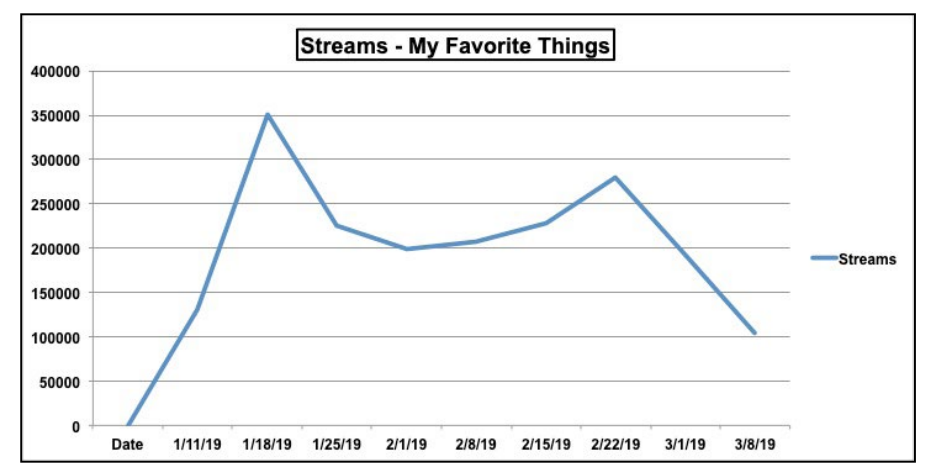

Figure 2: Streams of "My Favorite Things" (source: BuzzAngle Music 2019).

While the scale on the left is much smaller in Figure 2, the peak is clearly matching the streams recorded for " 7 Rings" in Figure 1. During the first week of the release of "7 Rings", the streaming for "My Favorite Things" increased by $168.74 \%$. Clearly the Ariana Grande fans were seeking out this song and listening. However, that was not all the fans were doing. They were also searching on Google (Figure 3).

Again, this reflects a marked increase during the first couple of weeks after the release. Given this information, it is easy to conclude that younger fans were indeed at least introduced to Rodgers and Hammerstein in a way that had not been achieved before.

As to Rodgers' and Hammerstein's opinion of Ariana 


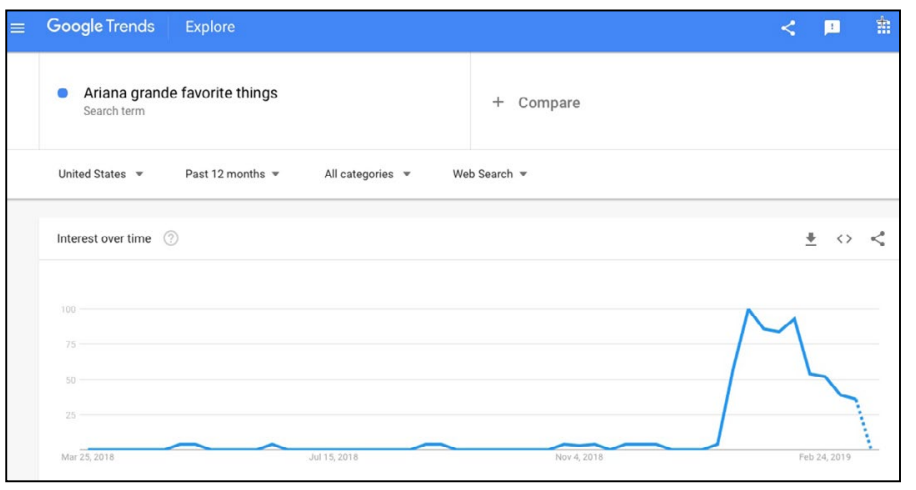

Figure 3. Google searches on "Ariana grande favorite things" from March 25, 2018 to February 24, 2019 (source: Google 2019).

Grande's song, one can only wonder. According to Purdum, "The masters of musical theatre enjoyed being in the thick of popular culture. But most important, he said, they were never ashamed of commercial success. 'They would love the ka-ching of it"' (Sisario 2019).

\section{References}

Brabec, Jeff, and Todd Brabec. 2018. Music, Money and Success: The Insider's Guide to making Money in the Music Business. New York: Schirmer Trade Books.

BuzzAngle Music. 2019. Accessed March 16, 2019. https://www.buzzanglemusic.com.

Cirisano, Tatiana. "Rodgers \& Hammerstein Earning 90\% of Ariana Grande '7 Rings' Songwriter Royalties." Billboard.com, March 19, 2019. Accessed March 20, 2019. https://www.billboard.com/articles/business/8503225/ariana-grande-7-rings-90-percent-songwriting-royalties-rodgers-hammerstein.

CK, "Gwen Stefani gets Fiddler approved." Jewlicious (blog), February 29, 2005. Accessed June 5, 2019. http://jewlicious.com/2005/02/gwen-stefani-gets-fiddler-approved/.

Hernandez, Ernio. "Singer Gwen Stefani Yodels Ode to Sound of Music on New Song 'Wind It Up'." Playbill. December 4, 2006. Accessed June 23, 2019. http:// www.playbill.com/article/singer-gwen-stefani-yodels-ode-to-sound-of-music-on-new-song-wind-it-upcom-136820.

Hershberg, Marc. "Rodgers and Hammerstein Top the Pop Charts." Forbes, February 7, 2019. Accessed March 15, 2019. https://www.forbes.com/sites/marchershberg/2019/02/07/rodgers-and-hammerstein-top-thepop-charts/\#71ed3fdf4284.

Huddleston, Jr., Tom. "Half a century later, the box office is alive with 'The Sound of Music'." Fortune, March 2, 2015. Accessed March 15, 2019. http://fortune. com/2015/03/02/sound-of-music-50-years/.

Jenkins, Craig. “Today's Biggest Pop Stars, Like Drake and the Weeknd, Are Walking the Line Between Stealing and Borrowing." New York, April 1-14, 2019 : 70-75.

Leight, Elias. “Ariana Grande's '7 Rings' Brings Rodgers and Hammerstein Back to Top 40." Rolling Stone, February 1, 2019. Accessed March 15, 2019. https:// www.rollingstone.com/music/music-features/arianagrande-7-rings-rodgers-hammerstein-sound-of-music-787196/.

Purdum, Todd S. 2018. Something Wonderful: Rodgers and Hammerstein's Broadway Revolution. New York: Henry Holt and Company.

Salzburg Panorama Tours. "Broadway Premiere, Success and Awards." Accessed March 17, 2019. https://www. sound-of-music.com/sound-of-music/broadway-musical/.

Singer, Jenny. "Ariana Grande's '7 Rings' - Satire Or A Big Misstep?" The Schmooze, January 18, 2019. Accessed March 15, 2019. https://forward.com/ 
schmooze/417783/ariana-grandes-7-rings-satire-or-a-

big-misstep/.

Sisario, Ben. "“7 Rings' Is a Hit for Ariana Grande, and a Knockout for Rodgers and Hammerstein." The New York Times, March 19, 2019. Accessed June 20, 2019. https://www.nytimes.com/2019/03/19/business/media/ ariana-grande-7-rings-rodgers-hammerstein.html.

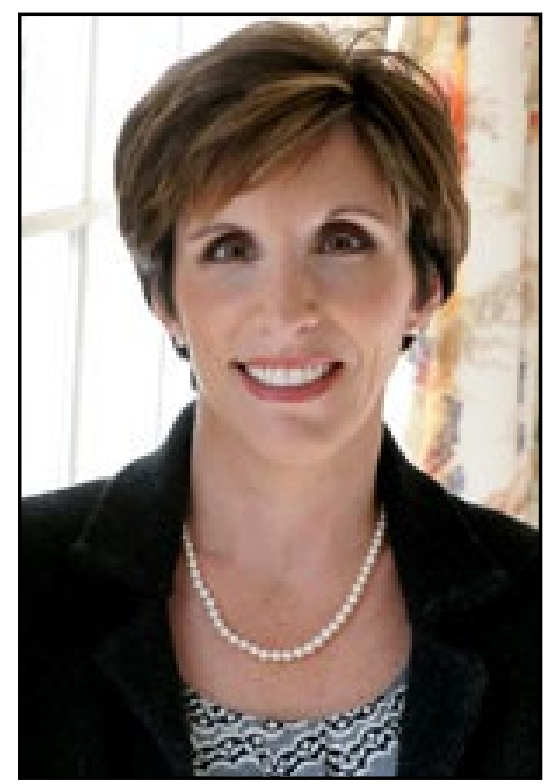

Melissa Wald is an associate professor in the Department of Recording Industry at Middle Tennessee State University (MTSU) where she teaches Music Publishing and Music Publishing Administration. She serves as a Music Business Area Coordinator as well as the Internship Coordinator for the Music Business and Commercial Songwriting concentrations.

Before her teaching career began at MTSU, she worked with several music publishing companies representing songs and songwriters from country music and Contemporary Christian music in Tennessee and Texas. Throughout her career, she has represented the songs of writers such as Alan Jackson, Amy Grant, Keith Urban, Steven Jones, Heidi Newfield, and Jim McBride. She continues her involvement in the industry by providing consulting and administrative services to several artists and songwriters in the areas of licensing, royalty calculation, and collection.

The Dallas native began her undergraduate studies at Baylor University as a piano and music education major but transferred to Belmont University to complete her Bachelor of Business Administration degree majoring in the Music Industry. She earned a masters in adult education and distance learning from the University of Phoenix and is a MEIEA board member, a member of the Leadership Music class of 2011 as well as SOURCE Nashville. 


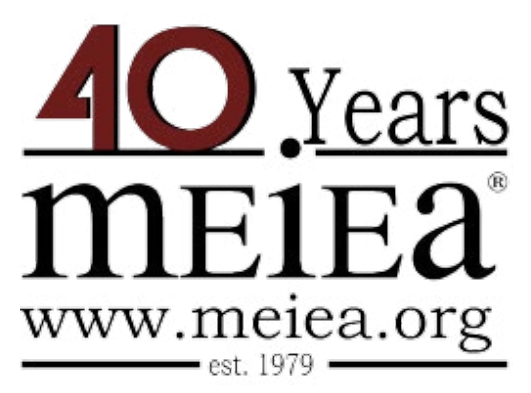

\section{PROCEEDINGS OF THE \\ 2019 INTERNATIONAL SUMMIT \\ OF THE \\ MUSIC \& ENTERTAINMENT \\ INDUSTRY EDUCATORS \\ ASSOCIATION}

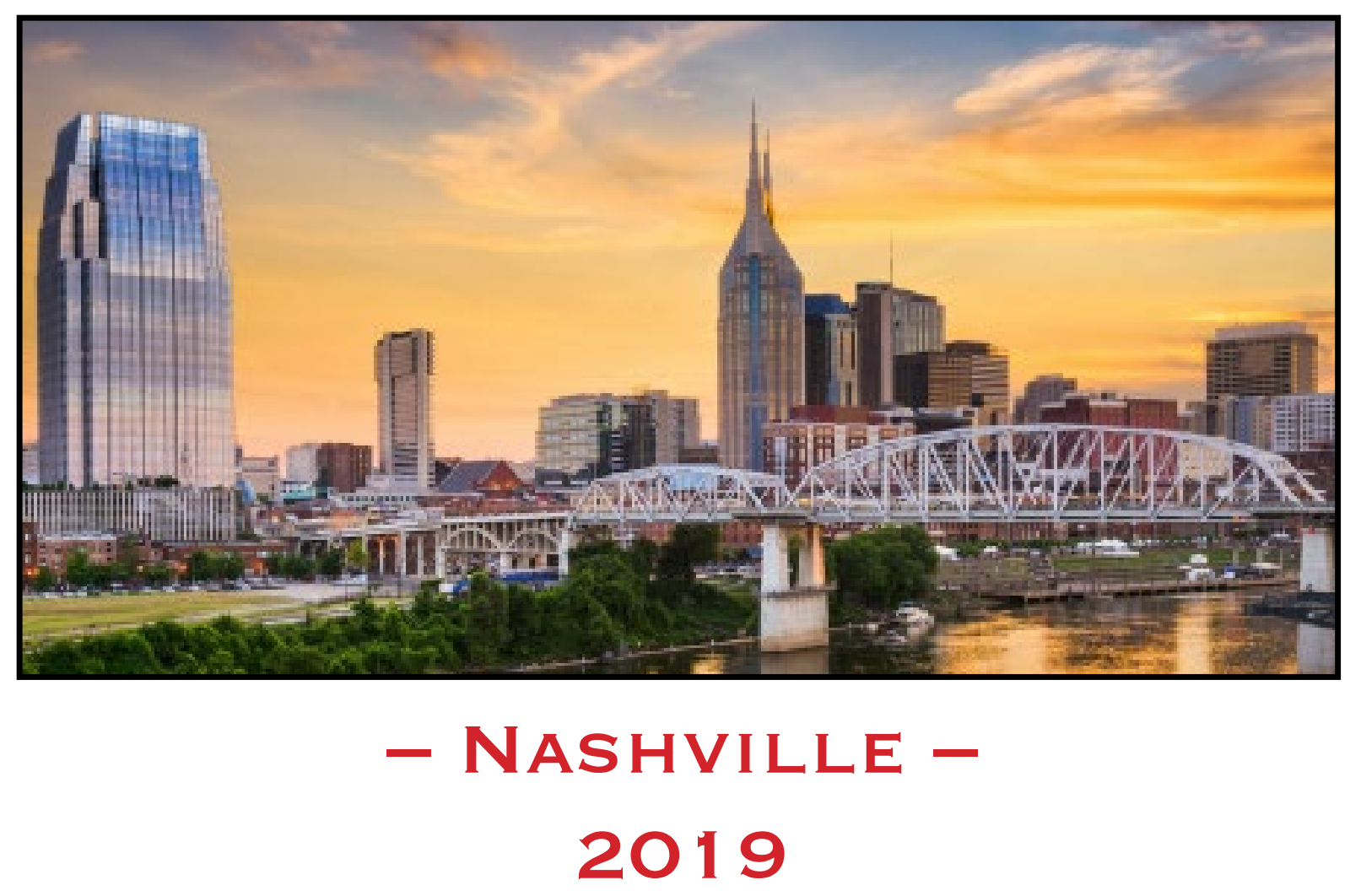

March 21 - 23, $2019 \cdot$ Belmont University - Nashville 